\title{
Incidence of thyroid disease in cases of hypertrophic cardiomyopathy
}

\author{
R. BELL, P. V. BARBER, C. L. BRAY, AND D. C. BETON \\ From the Department of Cardiology, Wythenshawe Hospital, Manchester
}

SUMMARY The investigative findings of patients considered to have possible hypertrophic cardiomyopathy were examined, and 31 of these fulfilling defined criteria for the disease were reviewed in detail, with emphasis on thyroid abnormalities. Four patients had a history of thyroid disease (13\%). Explanations considered for the apparent association were the effects of hyperthyroidism on normal, or more probably, incipiently abnormal myocardium.

That hyperthyroidism may produce or precipitate hypertrophic cardiomyopathy (HOCM) has been suggested by Symons et al. (1974), who cited supporting clinical and necropsy evidence. A patient with both conditions excited our interest in 1971, since when thyroid function tests have been performed on patients with suspected or proven HOCM. We present here the findings in a series of 31 cases where the diagnosis was validated, with details of thyroid function tests, and the incidence of clinical thyroid disease.

\section{Patients and methods}

Angiocardiograms, echocardiograms, and haemodynamic data were initially examined, and patients with positive features were called for outpatient review between November 1976 and May 1977. A symptomatic history was taken, concentrating on symptoms suggesting past hyperthyroidism, and a family history, including thyroid and autoimmune disorders. Clinical examination, chest $x$-ray film, electrocardiogram, and echocardiogram were repeated, and blood taken for thyroxine (T3 and T4), TSH, T3 resin uptake, and thyroid antibody screening.

Because most patients, when examined, were taking beta-adrenergic blocking drugs, clinical signs were rejected as criteria for inclusion in the study. An adequate, diagnostic, left ventricular angiogram was accepted, where available, but other previously described features presented difficulty. Braunwald and Aygen (1963) pointed out that left ventricular (LV) outflow obstruction might be

Received for publication 21 December 1977 absent, while echocardiographic asymmetric septal hypertrophy is not pathognomonic, occurring in primary pulmonary hypertension (Goodman et al., 1974), but absent in some otherwise typical cases. Similar doubts were cast, by Bulkley and Fortuin (1969) on systolic anterior movement of the anterior mitral valve leaflet while, in the absence of pulmonary hypertension, diastolic impingement of anterior mitral valve leaflet on the interventricular septum appears useful.

The agreed criteria were:

(1) Positive LV angiogram as defined by all of the following, (a) cone deformity ('carrot') of LV outflow tract; $(b)$ septal bulge in left anterior oblique view (LAO); (c) normal or high ejection fraction, or (2) Where angiographic views were inadequate or inappropriate (e.g. RAO projection) two of the following: (a) variable or latent $\mathrm{LV}$ outflow gradient exceeding $30 \mathrm{mmHg}$; (b) echocardiographic asymmetric septal hypertrophy with ratio 1.3 or more (Henry et al., 1973a); (c) echocardiographic systolic anterior movement and diastolic septal impingement of anterior mitral valve leaflet.

\section{Results}

(1) PATIENT CHARACTERISTICS

Among the patients reviewed, 31 (16 female and 15 male) fulfilled the diagnostic criteria. The mean age was 40 years, with a range of 14 to 68 years. Twentyfive patients were symptomatic, complaining of dyspnoea (22 patients), chest pains (18 patients, 9 related to effort), palpitation (17 patients), and dizziness (14 patients); only 1 reported effort syncope.

As expected, clinical signs, under beta-blockade, 


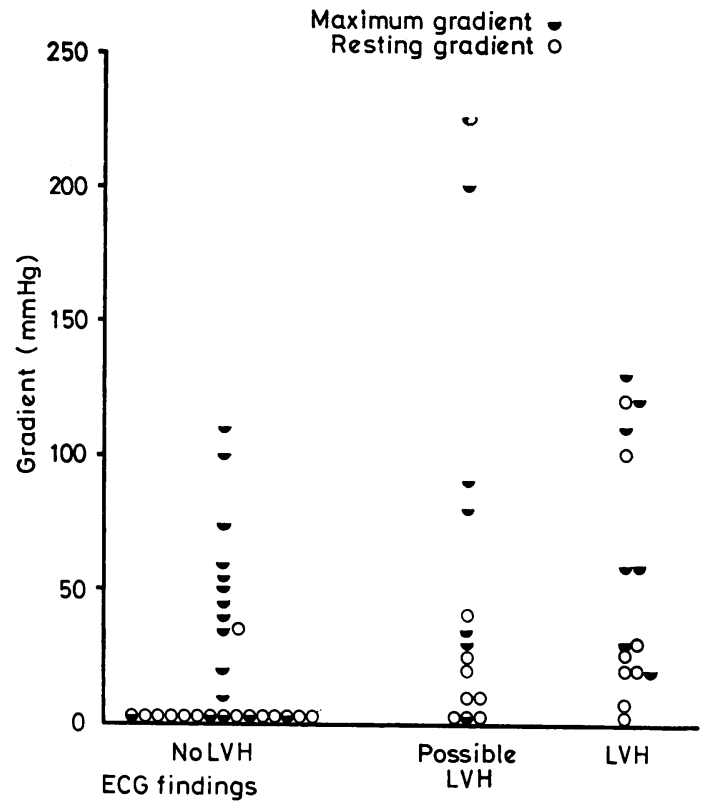

Fig. Electrocardiographic LV hypertrophy as defined by computer programme (Bonner et al., 1972) related to $L V$ outflow gradients. were frequently non-diagnostic, though 21 patients showed a mid to late systolic murmur. Radiologically, 15 cases showed pulmonary venous congestion, but aortic dilatation was seen in one case only. Electrocardiograms showed 'anterior infarction' patterns in 7 cases, and 'inferior infarction' in 2. LV hypertrophy changes are related to LV outflow gradients in the Figure, and, as found by Walston et al. (1971), all cases but one with resting gradients showed some evidence of left ventricular hypertrophy. The Table shows haemodynamic data available on 29 patients, cases 1 to 4 being those with a thyroid disease history (see below).

\section{(2) EVIDENCE FOR THYROID DISEASE}

Apart from one of the patients with known thyroid disease, thyroid function tests at review were normal, and thyroid antibodies negative.

Four patients had a history of thyroid disorder, and, apart from these, no symptomatic history to suggest previous undiagnosed hyperthyroidism was obtained. Two patients recalled their fathers having a goitre, and there were 2 cases of goitre and 1 of myxoedema described in extended families.

Table Haemodynamic data; gradients provoked using 5-10 $\mu$ isoprenaline (ISO)

\begin{tabular}{|c|c|c|c|c|c|c|c|c|c|}
\hline \multirow{3}{*}{$\begin{array}{l}\text { Case } \\
\text { no. }\end{array}$} & \multirow[t]{3}{*}{ Sex } & \multirow{2}{*}{\multicolumn{4}{|c|}{ Pressure (mmHg) }} & \multicolumn{4}{|c|}{ Gradients (mmHg) } \\
\hline & & & & & & \multicolumn{2}{|c|}{ Left outflow } & \multicolumn{2}{|c|}{ Right outflow } \\
\hline & & Aortic & $\overline{P C V}$ & LVED & $\overline{P A}$ & Resting & Isoprenaline & Resting & Isoprenaline \\
\hline 1 & $\mathbf{F}$ & $170 / 80$ & 8 & 10 & 20 & 0 & 0 & 0 & 20 \\
\hline 2 & $\mathbf{M}$ & $160 / 70$ & 5 & 8 & 20 & 0 & 0 & 0 & 25 \\
\hline 3 & $\mathbf{F}$ & $130 / 80$ & 13 & - & - & 0 & 45 & 0 & 0 \\
\hline 4 & $\mathbf{F}$ & $120 / 80$ & 6 & 5 & 19 & 0 & 75 & - & - \\
\hline 5 & $\mathbf{M}$ & $95 / 60$ & 2 & 3 & 7 & 5 & 60 & 50 & 95 \\
\hline 6 & $M$ & $120 / 75$ & 15 & 16 & 25 & 30 & 60 & - & - \\
\hline 7 & $\mathrm{~F}$ & $115 / 70$ & 9 & 12 & 14 & 0 & 10 & - & - \\
\hline 8 & $M$ & $120 / 75$ & - & 15 & 24 & \multicolumn{4}{|c|}{ Beta-blockade } \\
\hline 9 & $\mathbf{M}$ & $150 / 80$ & 8 & 10 & 14 & 0 & 0 & 0 & 10 \\
\hline 10 & $\mathrm{~F}$ & $140 / 60$ & 7 & 12 & 20 & 20 & 90 & 0 & 0 \\
\hline 11 & $M$ & $125 / 85$ & 4 & 9 & 13 & 10 & 30 & 10 & 10 \\
\hline 12 & $\mathrm{~F}$ & $125 / 75$ & 18 & 17 & 20 & 0 & 100 & 0 & 10 \\
\hline 13 & $\mathbf{F}$ & $130 / 80$ & 9 & - & 23 & \multicolumn{4}{|c|}{ Beta-blockade } \\
\hline 14 & $\mathbf{M}$ & $130 / 90$ & 12 & 10 & - & 35 & 55 & 15 & 30 \\
\hline 15 & $\mathbf{F}$ & $200 / 100$ & 25 & 40 & - & 0 & 0 & 10 & 10 \\
\hline 16 & $\mathbf{M}$ & $100 / 50$ & 17 & 26 & 18 & 40 & 225 & 9 & 15 \\
\hline 17 & $\mathbf{F}$ & $70 / 35$ & 22 & 17 & 34 & 90 & 230 & - & - \\
\hline 18 & $\mathrm{~F}$ & $125 / 85$ & 8 & 12 & 20 & 0 & 20 & 0 & 0 \\
\hline 19 & $M$ & $140 / 77$ & 6 & 2 & 13 & 10 & 80 & 15 & 30 \\
\hline 20 & M & $140 / 80$ & 7 & 5 & 12 & 0 & 40 & - & - \\
\hline 21 & $\mathbf{F}$ & $155 / 88$ & 13 & - & 24 & 0 & 10 & 0 & 0 \\
\hline 22 & M & $75 / 50$ & 5 & 7 & 14 & 20 & 30 & 0 & 15 \\
\hline 23 & $\mathrm{~F}$ & $115 / 70$ & 11 & 12 & 14 & 0 & 60 & 4 & 10 \\
\hline 24 & $\mathbf{M}$ & $125 / 75$ & 15 & 14 & 20 & 20 & 110 & 10 & 25 \\
\hline 25 & $\mathbf{F}$ & $140 / 80$ & 15 & 18 & 20 & 0 & 110 & 0 & 12 \\
\hline 26 & $\mathbf{M}$ & $100 / 70$ & 9 & 12 & 11 & 0 & 200 & 0 & 0 \\
\hline 27 & M & $180 / 110$ & 13 & - & - & 120 & 120 & - & - \\
\hline 28 & $\mathbf{F}$ & $160 / 90$ & 22 & 45 & 40 & 25 & 25 & - & - \\
\hline 29 & $\mathbf{F}$ & $170 / 90$ & 7 & 8 & 15 & 0 & 45 & 0 & 0 \\
\hline
\end{tabular}

Key to pressures: $\overline{\mathrm{PCV}}$ mean pulmonary capillary venous (wedge), LVED left ventricular end diastolic, $\overline{\mathrm{PA}}$ mean pulmonary artery. 


\section{(3) CASE HISTORIES}

\section{Case 1}

A 49-year-old multiparous housewife was admitted in 1973, during an episode of chest pain, associated with sinus tachycardia and a blood pressure of $200 / 100 \mathrm{mmHg}$. Clinical LV hypertrophy was associated with a loud praecordial ejection systolic murmur. Electrocardiogram showed left bundlebranch block, and cardiac enzymes were normal. Serum T4 was $157 \mathrm{nmol} / \mathrm{l}$ with T3 resin uptake 94 per cent (then in the laboratory's hyperthyroid range) and 2-hour radioiodine uptake was confirmatory at 44 per cent.

Subsequent LV angiogram showed cone deformity of the outflow tract, septal bulge, and, though no left-sided gradient was shown, a right ventricular (infundibular) gradient of $20 \mathrm{mmHg}$ was induced by isoprenaline. An adequate echocardiogram was not obtainable. Ten months treatment with carbimazole was effective, without ensuing recurrence of hyperthyroidism.

\section{Case 2}

A 61-year-old male paint tinter presented in December 1976, with a 3-month history of chest pain on effort, sweating, and the loss of $1.3 \mathrm{~kg}$ in weight. He showed a bounding pulse, BP 200/60 $\mathrm{mmHg}$, a distinct ejection systolic murmur, and had a normal electrocardiogram. Serum T4 was $224 \mathrm{nmol} / 1$ (35 to 140) with free thyroxine index 298 ( 35 to 140 ) and T3 resin uptake 75 per cent ( 85 to 125). Left ventricular angiography showed cone deformity, septal hypertrophy, and increased ejection, while no LV gradient, but a right ventricular, infundibular gradient of $25 \mathrm{mmHg}$ was provoked by isoprenaline. Echocardiography indicated systolic anterior movement, and septal impingement of anterior mitral valve leaflet, and asymmetric septal hypertrophy with a septum/free wall diastolic ratio of $2 \cdot 0$. All symptoms improved after treatment with radioiodine.

Case 3

A 35-year-old housewife complained in 1971 of episodic palpitation in her fourth pregnancy, and these persisted with effort chest pain after delivery, despite practolol therapy. Examination disclosed a normal pulse form, and an ejection systolic murmur. Electrocardiogram was normal, LV angiogram showing septal hypertrophy, with cone deformity, and a latent LV outflow gradient of 40 to $50 \mathrm{mmHg}$ was shown with isoprenaline. There was echocardiographic asymmetric septal hypertrophy (ratio 1.37).

In 1973 , her anxiety raised the question of hyper- thyroidism, and serum T4 consistently exceeded $160 \mathrm{nmol} / 1$ (then in the laboratory's toxic range). Carbimazole resulted in improvement in anxiety, but not in angina. It was discontinued after 18 months, and, though free thyroxine index was slightly raised subsequently at 148 , she was clinically euthyroid.

\section{Case 4}

This 68-year-old housewife was referred in 1976, after an outpatient visit for peripheral vascular disease, where a history of longstanding anginal symptoms and a systolic murmur were noted. She also reported exertional dizziness and weight loss. The pulse was bounding, BP $190 / 40 \mathrm{mmHg}$, and a grade 2 ejection systolic murmur was present. Electrocardiogram showed voltage criteria for $\mathrm{LV}$ hypertrophy, with lateral ischaemia. LV angiography showed a very small cavity, septal bulge, and outflow tract cone deformity, while a latent LV outflow gradient of $75 \mathrm{mmHg}$ was seen with isoprenaline.

Serum T4 was $191 \mathrm{nmol} / 1$ (35 to 150) with T3 resin uptake 83 per cent and free thyroxine index 230 (35 to 150). Thyrotoxic symptoms recurred after 9 months carbimazole, and radioiodine uptake at 2 hours was increased at 48 per cent. Radioiodine therapy is now being considered.

Among patients excluded from the series because diagnostic criteria for HOCM were not entirely fulfilled, was one woman with a history of thyroid disease, though records of radioiodine therapy in 1961 were untraceable. She showed an increased ejection fraction on RAO angiogram, a variable $\mathrm{LV}$ outflow gradient reaching $120 \mathrm{mmHg}$ with isoprenaline, and probable septal hypertrophy on poorly defined echocardiograms. TSH was increased at review, at $11.0 \mathrm{mU} / 1$ (less than 6.0 ).

\section{Discussion}

The difficulties of diagnosing clinically hyperthyroidism with HOCM have been outlined by Symons et al. (1974). Cardiac catheterisation findings in our cases were unremarkable, except that 2 of the patients with thyroid disease (cases 1 and 2) showed right ventricular, infundibular gradients in the absence of any left-sided gradient, a feature of only 2 other cases in the series.

It is difficult to validate clinical associations by comparison with controls in a series of this size, and we did not attempt this. Nevertheless, an incidence of 13 per cent of cases having thyroid disease appears largely to be a chance finding. If genuine, the connection has a number of possible explanations. One is that increased circulating thyroid hormones may 
produce HOCM in a previously normal heart. It has recently been shown, by Olsen et al. (1977), working with pregnant rats, that thyroxine analogues can produce, in the offspring, ultrastructural changes in the myocardium similar to those of HOCM. This was more pronounced with larger doses, and no such changes occurred in adult rats, even on high dose regimens. The connection with human disease is not clear, and a history of maternal thyroid disease was not noted in any of our patients. Electrocardiographic evidence of severe LV hypertrophy appears uncommon in thyrotoxic heart disease, though some myocardial hypertrophy (occasionally severe) is well recognised at necropsy. These observations accord with the cardiac effects of hyperthyroidism, probably arising from thyroid hormone activity, rather than induced catecholamine hypersensitivity (Aoki et al., 1972).

Another possibility is that hyperthyroidism exacerbates or precipitates HOCM where there is an incipient myocardial abnormality. Symons et al. (1974) described 3 cases with both conditions, and in 2 of them myocardial histology indicated HOCM in 1, but was non-specific in the other.

Since even severe hyperthyroidism does not consistently result in HOCM, the second explanation appears the more probable, and the high incidence of echocardiographic abnormalities found by Henry et al. (1973b) in first degree relatives of HOCM patients suggests, firstly, that most, possibly all, cases have a hereditary basis, and, secondly, that some additional factor may be needed to produce clinical disease. Further information may accrue from echocardiographic screening of a thyrotoxic population.
We should like to thank Mrs C. Wrigley for performing the many additional echocardiograms.

\section{References}

Aoki, V. S., Wilson, W. R., and Theilen, E. O. (1972). Studies of the reputed augmentation of the cardiovascular effects of catecholamines in patients with spontaneous hyperthyroidism. Fournal of Pharmacology and Experimental Therapeutics, 181, 362-368.

Bonner, R. E., Crevasse, L., Ferrer, M. I., and Greenfield, J. C. (1972). A new computer program for analysis of scalar electrocardiograms. Computers and Biomedical Research, 5, 629-653.

Braunwald, E., and Aygen, M. (1963). Idiopathic myocardial hypertrophy without congestive heart failure or obstruction to blood flow. American fournal of Medicine, 35, 7-19.

Bulkley, B. H., and Fortuin, N. J. (1969). Systolic anterior motion of the mitral valve without asymmetric septal hypertrophy. Chest, 69, 694-696.

Goodman, D. J., Harrison, D. C., and Popp, R. L. (1974). Echocardiographic features of primary pulmonary hypertension. American fournal of Cardiology, 33, 438-443.

Henry, W. L., Clark, C. E., and Epstein, S. E. (1973a). Asymmetric septal hypertrophy. Echocardiographic identification of the pathognomonic anatomic abnormality of IHSS. Circulation, 47, 225-233.

Henry, W. L., Clark, S. E., and Epstein, S. E. (1973b). Asymmetric septal hypertrophy (ASH): the unifying link in the IHSS disease spectrum. Circulation, 47, 827-832.

Olsen, E. G. J., Symons, C., and Hawkey, C. (1977). Effect of triac on the developing heart. Lancet, 2, 221-223.

Symons, C., Richardson, P. J., and Feizi, O. (1974). Hypertrophic cardiomyopathy and hyperthyroidism. Thorax, 29, 713-719.

Walston, A., II, Behar, V. S., Wagner, G. S., and Greenfield, J. C., Jr. (1971). Electrocardiographic and haemodynamic correlations in patients with idiopathic hypertrophic subaortic stenosis. American Heart fournal, 91, 11-17.

Requests for reprints to Dr R. Bell, Hope Hospital, Eccles Old Road, Salford M6 8HD, Lancs. 


\section{Echocardiographic identification of aorta and main pulmonary artery in complete transposition}

Sir,

A. B. Houston et al. (British Heart fournal, 40, 377-382) describe the echocardiographic identification of aorta and main pulmonary artery in complete transposition with beautiful pictures.

It is easy to identify the aorta in transposition if you can recognise the brachiocephalic trunk arising from the anterior vessel. This is particularly so in the more complex anomalies such as transposition with pulmonary atresia. Strangely enough, Houston does not mention this sign though his Fig. 4 (page 379) is a beautiful example.

O. Daniëls,

Dept. of Paediatric Cardiology,

Universiteitsklinik voor Kindergeneeskunde, Nijmegen,

Holland.
This letter was shown to Dr Houston and his co-authors who reply as follows:

Sir,

We agree with Dr Daniëls, but since we have not always been able to visualise the brachiocephalic trunk (innominate artery) we have been unwilling to put this forward as a feature on which we may depend when identifying the aorta.
A. B. Houston,
N. L. Gregory, and E. N. Coleman, Royal Hospital for Sick Children, Yorkhill, Glasgow G3 8SJ.

\section{Erratum}

Volume 40 (1978) pages 1306-1309: the authors have asked us to point out an error in their paper on 'Incidence of thyroid disease in cases of hypertrophic cardiomyopathy'. On page 1308, line 13 of the Discussion, the word 'largely' was printed in error for 'large'. 